\title{
APOIO INSTITUCIONAL PAIDEIA COMO ESTRATÉGIA PARA EDUCAÇÃO PERMANENTE EM SAÚDE
}

\author{
PAIDEIA INSTITUTIONAL SUPPORT AS A STRATEGY FOR CONTINUOUS EDUCATION IN HEALTH \\ APOYO INSTITUCIONAL PAIDEIA COMO ESTRATEGIA PARA LA EDUCACIÓN CONTINUA EN LA SALUD
}

Cristiane Pereira de Castro ${ }^{1}$

Gastão Wagner de Sousa Campos ${ }^{2}$

Resumo Trata-se de uma pesquisa-intervenção do tipo apoio. Nesta investigação, avaliaram-se os efeitos do curso-intervenção Cogestão da Clínica Ampliada e Compartilhada, especialmente no que se refere à incorporação de saberes que auxiliam os profissionais a desenvolverem a capacidade de trabalhar em rede, em equipe e com cogestão do trabalho em saúde. O curso foi oferecido aos profissionais que compunham as equipes do Centro de Saúde Aeroporto e do Centro de Atenção Psicossocial David Capistrano e a apoiadores institucionais do Distrito Sudoeste de Campinas, São Paulo. Para a produção de dados, utilizaram-se duas técnicas: observação e realização de grupos focais de avaliação com os profissionais que participaram do curso. Constataram-se mudanças relevantes nos profissionais no que diz respeito às dimensões clínica, político-institucional e do governo de si mesmos.

Palavras-chave formação em saúde; apoio institucional; Método Paideia; educação permanente em saúde.
Abstract This is a support-type research intervention. This study evaluated the effects of the Extended and Shared Clinic Comanagement course-intervention, especially with regard to the incorporation of knowledge that helps professionals develop the ability to network, to work in teams, and to co-manage health work. The course was offered to professionals comprising the Airport Health Center and the David Capistrano Psychosocial Care Center teams and institutional supporters of the Southwest District of Campinas, São Paulo. Two techniques were used to generate the data: Observation and conducting assessment focus groups with the professionals who took part in the course. Relevant changes were noted among the professionals with regard to their own clinical, political-institutional and government dimensions.

Keywords Health education; institutional support; Paideia Method; continuing health education. 


\section{Introdução}

Este artigo $^{3}$ pretende descrever e analisar uma maneira de lidar com a formação de pessoal em serviços ligados ao Sistema Único de Saúde (SUS), utilizando o Método de Apoio Institucional Paideia como estratégia para a educação permanente em saúde.

A educação permanente em saúde constitui estratégia fundamental para as transformações do trabalho no setor saúde, a fim de que ele se torne lugar de crítica reflexiva, propositiva, compromissada e tecnicamente competente (Ceccim, 2005).

O apoio institucional é uma aplicação metodológica da concepção Paideia desenvolvida por Campos (2005), na tese intitulada Um método para análise e cogestão de coletivos. O autor parte de uma crítica à tradição da racionalidade gerencial hegemônica, propondo uma concepção ampliada da gestão e do trabalho em saúde, fundamentada na análise crítica da teoria política, da administração e planejamento, da análise institucional e da pedagogia. O autor propõe uma reforma e a aproximação entre a gestão e as práticas de saúde, apostando no desenvolvimento de uma gestão democrática - a cogestão - e incentivando a participação dos sujeitos em coletivos organizados voltados para a produção de bens ou serviços, bem como para a educação permanente e para a gestão compartilhada da instituição e de seus processos de trabalho.

A proposta do curso foi aplicar o apoio institucional como estratégia pedagógica. Como na gestão, buscou-se construir conhecimentos com base na experiência concreta dos profissionais matriculados no curso. Optou-se pela discussão de casos clínicos ou institucionais trazidos pelos profissionais, com os professores funcionando como apoiadores horizontais, isto é, tanto facilitando a discussão dos casos e a elaboração dos projetos terapêuticos ou de intervenção quanto trazendo ofertas teóricas ou estimulando a problematização, ligando cada caso à estratégia geral de formação.

Segundo Campos (2005), o Método de Apoio Paideia tanto pode ser autoaplicável quanto contar com a figura de um ou mais apoiadores horizontais (externos). O autor destaca que há vantagens e desvantagens em cada uma das situações. A presença de um apoiador externo ou horizontal implica sempre a possibilidade de controle sobre o grupo; por outra parte, facilita a abertura de linhas de comunicação truncadas (papel do mediador) e amplia o leque de ofertas que o grupo tem de considerar e com as quais precisa lidar (incorporação crítica de racionalidade e demandas estranhas à equipe).

A função de apoio institucional/horizontal, além de incidir sobre a gestão e o acúmulo de conhecimentos cognitivos, propõe-se também a colaborar para a formação dos sujeitos. O conceito paideia, buscado da Grécia Clássica, refere-se a um aprendizado significativo, isto é, um aprendizado 
que abranja dimensões técnicas, políticas, éticas e do próprio cogoverno de si mesmo. O método utiliza o conceito de coprodução, ou seja, o ser humano entendido enquanto produto e produtor de si mesmo, vivenciando um processo dialético e dinâmico (Campos, 2005).

Para alcançar tal objetivo, o método propõe um conjunto de arranjos e dispositivos que favoreçam a participação dos sujeitos na gestão de seus processos de trabalho e na própria organização - no caso, o espaço coletivo privilegiado foi a própria turma de alunos. O espaço coletivo, isto é, a turma de alunos é um arranjo reflexivo e deliberativo, formado por um conjunto de pessoas que estejam inseridas numa organização e se encontrem envolvidas com a produção de algum bem ou serviço que tenha valor de uso para a sociedade. Essa estratégia de formação é uma forma de favorecer a cogestão, configurando uma tentativa de trabalhar os diferentes saberes, poderes e afetos.

Nosso grupo de pesquisa, o Coletivo de Estudos e Apoio Paideia do Departamento de Saúde Coletiva, da Faculdade de Ciências Médicas da Universidade Estadual de Campinas (Unicamp) ofereceu o curso denominado Cogestão da Clínica Ampliada e Compartilhada, como estratégia pedagógica de formação: uma fusão do método de apoio com a metodologia utilizada por Balint (1988; ver também Cunha, 2009) para a formação de médicos generalistas na Grã-Bretanha. O curso foi oferecido ao coletivo de trabalhadores de uma das unidades básicas do SUS de Campinas. Alguns pesquisadores funcionaram como apoiadores horizontais durante todo o processo.

$\mathrm{O}$ apoio institucional recomenda uma interação dialógica entre equipe e apoiadores, na qual tanto uns quanto outros opinem sobre práticas em saúde e sobre a gestão. O apoio centra o processo reflexivo na prática dos profissionais, tratando de articular essa análise com elementos teóricos. Balint (1988) utiliza a discussão coletiva de casos clínicos com objetivos semelhantes. No curso, ampliamos o conceito de caso, incluindo tanto projetos terapêuticos quanto projetos voltados para coletivos ou mesmo de ordem institucional.

Portanto, buscou-se criar espaços para que as equipes da unidade básica fizessem análise de sua sociabilidade e da instituição SUS; objetivava-se com isso, por meio da reflexão sobre a própria prática, contribuir para que os profissionais pudessem ampliar sua capacidade reflexiva e adquirir maior capacidade de interferir nos fatores estruturados que os condicionavam.

\section{Metodologia}

Trata-se de uma pesquisa-intervenção (Rocha e Aguiar, 2003) cujo objeto de investigação foi o estudo de efeitos do Apoio Institucional Paideia sobre a 
formação dos profissionais matriculados no Curso de Cogestão da Clínica Ampliada e Compartilhada, também denominado curso-intervenção.

O curso-intervenção foi coconstruído pelo grupo de pesquisa Coletivo de Estudos e Apoio Paideia, em diálogo com profissionais de saúde da rede municipal, e coordenado pelo Distrito Sudoeste e pelo Centro de Educação dos Trabalhadores da Saúde da Secretaria Municipal de Saúde de Campinas.

Foi oferecido como curso de extensão da Universidade Estadual de Campinas e realizado de forma descentralizada, ou seja, em vários serviços de saúde da rede municipal. Investigamos o curso ministrado no Centro de Saúde Jardim Aeroporto, localizado no Distrito Sudoeste da cidade de Campinas, que foi coordenado por dois apoiadores horizontais, entre eles a própria pesquisadora, vinculados ao Departamento de Saúde Coletiva da Unicamp, sob a supervisão direta do professor Gastão Wagner de Sousa Campos.

O curso-intervenção teve duração de um ano e meio: iniciou-se em junho de 2009 e encerrou-se em dezembro de 2010. Realizaram-se 18 encontros, a cada trinta dias, com duração de duas horas cada um. Foram compostas duas turmas, denominadas $\mathrm{A}$ e B, com no máximo 20 pessoas. O cronograma e o programa foram pactuados com os profissionais matriculados. Em cada encontro, os profissionais apresentavam casos sobre sua responsabilidade. O modelo de apresentação de casos foi o mesmo utilizado para projetos terapêuticos ou para projetos de intervenção (Cunha, 2009), isto é, além de se buscar uma compreensão do problema, tentava-se sempre apontar linhas práticas a serem executadas pelas equipes. Em geral, o estudo da bibliografia, e os aportes teóricos obedeceram a temas surgidos da reflexão sobre os casos.

Vale ressaltar que o nosso grupo de pesquisa foi convidado pelo Distrito Sudoeste da Secretaria Municipal de Saúde de Campinas por causa de sua proximidade com relação ao trabalho já desenvolvido, pautado no desenvolvimento de gestões democráticas, participativas, autônomas e fundadas na ética da atenção à saúde.

A escolha dos profissionais que integraram o curso-intervenção foi discutida com a coordenação do Distrito Sudoeste. Definiu-se que os participantes seriam profissionais que compõem as quatro equipes de saúde da família e ainda das equipes matriciais de saúde mental do Centro de Saúde Aeroporto (CS Aeroporto), Centro de Apoio Psicossocial David Capistrano (CAPS David) e apoiadores institucionais do Distrito Sudoeste.

Os critérios para a inclusão de sujeitos na pesquisa obedeceram aos seguintes requisitos: profissionais do Centro de Saúde Jardim Aeroporto ou do Centro de Apoio Psicossocial David Capistrano ou do Distrito Sudoeste, em função direta de atenção à população ou em cargos de gestão da clínica; todos deveriam estar matriculados no Curso de Cogestão da Clínica Ampliada e Compartilhada. Foram excluídos do estudo todos que tiveram frequência ao curso inferior a $75 \%$. 


\section{Pesquisa-intervenção do tipo apoio}

O projeto, aprovado pelo Comitê de Ética da Faculdade de Ciências Médicas, se insere no campo das pesquisas qualitativas participativas, em particular no da pesquisa-intervenção. Essa tradição epistemológica reconhece, simultaneamente, a interferência da visão de mundo do pesquisador em sua aproximação ao objeto e à metodologia (Minayo, 2000). Também assegura a participação dos agentes envolvidos nas práticas estudadas, de forma que também possam analisar a situação e criar novas formas de agir diante dos problemas e indagações levantados pela pesquisa (Brandão, 1981; Gajardo, 1999; Monceau, 2005).

O projeto articulou pressupostos das pesquisas de intervenção de caráter participativo à rede de conceitos e de recursos metodológicos do Apoio Institucional Paideia (Campos, 2005). Essa composição objetivou compor uma metodologia de investigação que analisasse a dinâmica dos coletivos e, ao mesmo tempo, interviesse no seu desenvolvimento com base na emergência de temas relevantes ao contexto. Os profissionais/alunos foram estimulados a construírem, analisarem e interpretarem textos, buscando com esse procedimento a elaboração de novos sentidos e significados que orientem o agir concreto dos sujeitos envolvidos. Essa metodologia híbrida, por nós denominada pesquisa-intervenção do tipo apoio, foi assim definida por Massuda:

Uma pesquisa prática, tipo pesquisa-intervenção, que objetiva a produção de conhecimentos científicos mediante o processo de intervenção junto a coletivos organizados, em que se utiliza o Método de Apoio Paideia (2010, p. 80).

\section{A produção de dados e a interpretação compartilhada do material produzido em campo}

Diante das características do objeto em estudo, os efeitos do Curso intervenção sobre as práticas dos profissionais matriculados, foram utilizados duas técnicas para produção de dados qualitativos.

A primeira foi a observação direta do processo de formação realizada pela pesquisadora-apoiadora responsável pelo curso-intervenção no Centro de Saúde Jardim Aeroporto, turmas A e B, que utilizou diário de campo para registro sistemático das observações. Segundo Minayo (2005), mediante a observação é possível identificar movimentos, símbolos e sinais significativos do processo em investigação, muitas vezes naturalizados no cotidiano. Assim, o diário de campo da pesquisadora foi organizado de forma a contemplar dois focos. O primeiro foram as anotações sobre os casos apresentados e sobre os comentários realizados durante os encontros do curso-intervenção; o segundo, a descrição das impressões gerais da pesquisadora-apoiadora ao final de cada encontro. 
A segunda forma de produção de dados baseou-se no próprio discurso dos profissionais/alunos. Com essa finalidade, realizaram-se grupos focais de avaliação do processo de formação com os profissionais matriculados no curso-intervenção. O primeiro momento de avaliação coletiva foi em dezembro de 2009; o segundo ocorreu em novembro de 2010.

Segundo Morgan (1997), os grupos focais são uma técnica de pesquisa que capta o discurso por meio das interações grupais ao se discutir um tópico especial sugerido pelo pesquisador. No caso da presente pesquisa, o objetivo da realização do grupo focal foi avaliar as contribuições do Método de Apoio Paideia e do curso-intervenção na formação dos profissionais matriculados.

É importante destacar que o roteiro do grupo focal foi construído pelo Coletivo de Estudos e Apoio Paideia, dando-se destaque a três eixos: 1) repercussões do curso sobre o trabalho em equipe e as práticas em saúde; 2) funcionamento dos arranjos de gestão; e 3) cogestão de 'si mesmo'.

Foram realizados quatro grupos focais, dois para cada uma das turmas, sempre com a presença dos profissionais matriculados no curso-intervenção, de um moderador externo, responsável por coordenar o grupo, e de um relator para auxiliar, e que se responsabilizou por anotar o início das falas dos participantes, as conversas paralelas e os comentários complementares.

Ressalte-se que a coordenação dos grupos focais foi realizada por membros do Coletivo de Estudos e Apoio Paideia que não operassem como apoiadores daquele grupo de profissionais.

O material produzido em campo foi trabalhado pelos pesquisadores, objetivando a construção de narrativas, tal como proposta por Ricœur (1997). Para esse autor, as narrativas são histórias não narradas (ainda), mas que podem ser contadas porque já estão inseridas no mundo pelo agir social, estando simbolicamente mediatizadas.

Pretendeu-se com os dados primários obtidos pela transcrição do grupo focal construir uma narrativa sobre a história vivenciada pelos profissionais/alunos. No momento da interpretação, a pesquisadora autorizou-se a realizar uma triangulação dessas narrativas com os dados obtidos pela observação. Com isso, buscou-se juntar as linhas argumentativas extraídas das narrativas sobre o processo de formação de modo a construir o enredo singular de cada turma e situação observada.

Tomou-se o cuidado, exigido pelos cânones da pesquisa participativa, de compartilhar as narrativas construídas pelos pesquisadores com o grupo de profissionais/alunos. Cada síntese elaborada com base nos grupos focais foi devolvida ao próprio grupo para que ele criticasse e validasse a narrativa. Esses espaços foram denominados momento reflexivo. Destaque-se que, nesse momento, o material apresentado pelos pesquisadores poderia ser complementado ou modificado, e os profissionais matriculados (sujeitos da pesquisa) puderam confirmar posições, rever argumentos, discutir diferen- 
ças entre aquilo que disseram e o modo como foram compreendidos e reposicionarem-se diante do próprio discurso e da tradição discursiva que os sustentava (Onocko, 2005).

Figura 1

Percurso da pesquisa
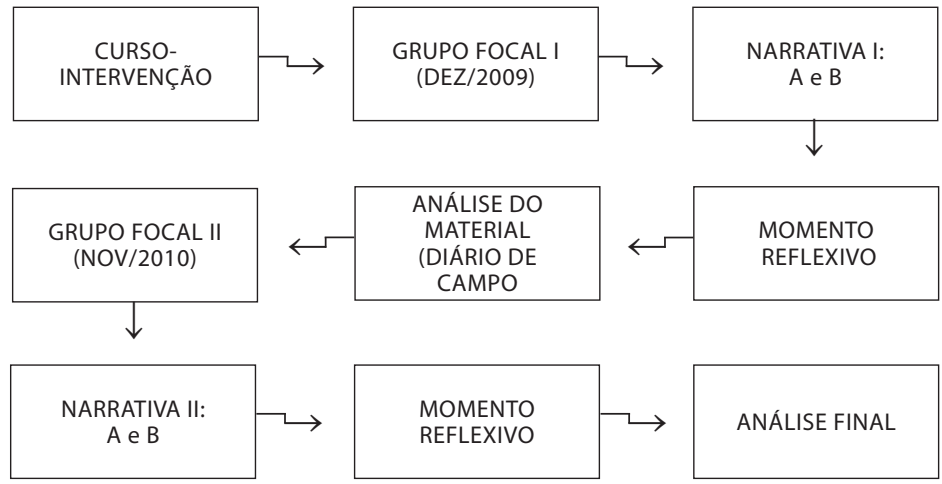

Fonte: Os autores.

\section{Desenvolvimento da pesquisa}

Deve-se apontar que houve vários percalços políticos e de gestão durante o transcurso do curso-intervenção, e isso trouxe consequências para o processo de formação. Dentre esses eventos/processos, ressaltou-se a greve dos servidores públicos municipais, que teve a adesão da maioria dos profissionais matriculados no curso-intervenção e se estendeu por quase noventa dias. O curso-intervenção não foi suspenso, mas houve um esvaziamento, visto que as assembleias aconteciam no período vespertino e os profissionais que permaneciam no serviço acabavam ficando com a tarefa de atender à demanda e orientar os usuários, fatos que muitas vezes impossibilitaram a participação nos encontros.

A pandemia de influenza A trouxe a necessidade das equipes do Centro de Saúde Jardim Aeroporto de modificar alguns processos de trabalho, por causa do aumento da demanda. Com isso, inúmeras vezes, por sobrecarga, os profissionais matriculados no curso-intervenção optaram por não comparecer aos encontros, ainda que esses ocorressem dentro do serviço. Além disso, durante o curso-intervenção, as interrupções e saídas foram constantes. 
Concomitantemente, o término do contrato temporário de cinco das seis enfermeiras do Centro de Saúde trouxe um panorama de insegurança e incerteza entre todos os trabalhadores da unidade, dificultando o planejamento a médio e longo prazos. A saída dessas cinco enfermeiras repercutiu negativamente no curso-intervenção e resultou em uma reorganização radical do horário de trabalho de diversos profissionais matriculados.

Houve vários momentos, durante o processo de formação, nos quais foram debatidos os efeitos desse contexto sobre os profissionais, sobre o curso e sobre a própria instituição. Comentou-se a sensação de desmotivação, e os profissionais matriculados reconheceram que aquele espaço de formação, ainda que não fosse valorizado pelos dirigentes do SUS, havia se transformado em um investimento deles mesmos, com potência de transformar, em alguma medida, a realidade vivenciada.

Pode-se afirmar que o contexto institucional interferiu negativamente, mas não trouxe paralisia. As dificuldades institucionais foram debatidas, analisadas e compreendidas como um fator limitante, mas não definidor do processo de formação que era vivenciado.

\section{Análise de resultados}

A presente investigação permitiu algumas reflexões sobre as potencialidades e limites da utilização do Apoio Institucional Paideia como estratégia de educação permanente em saúde. Essas considerações levaram em conta o contexto institucional do SUS Campinas que, por um lado, possibilitou a realização de um curso que se propunha a criticar e a interferir na gestão, mas que, por outro, gerou uma série de eventos negativos.

Observou-se que o apoio institucional, a pesquisa e o curso-intervenção, por causa da utilização de estratégias dialógicas, reflexivas e de cogestão, obrigaram os profissionais matriculados e a pesquisadora-apoiadora, estimulados pelas narrativas e pelo diário de campo, a alto grau de comunicação, que se entrelaçou e criou, pode-se dizer, vida própria para além do programa e do contrato iniciais.

Discutiremos os resultados organizados em alguns eixos: mudanças observadas na dimensão profissional, na dimensão política/institucional e na dimensão do governo de si mesmo.

\section{A dimensão profissional}

Os profissionais matriculados no curso-intervenção fizeram referências explícitas e taxativas ao impacto produzido pelo processo em suas práticas em saúde. Referiram-se à incorporação de novas e diferentes formas no cuidado, 
bem como na compreensão sobre o processo saúde-doença. Citaram como exemplo o reconhecimento da família como espaço de intervenção tanto para a promoção quanto para a clínica; comentaram a importância de se valorizarem as ofertas de grupos educativos e terapêuticos no interior dos serviços; e reconheceram ter havido ampliação dos olhares sobre o tema do território e sobre os limites e potencialidades do apoio matricial. Tais mudanças foram viabilizadas pelas discussões ocorridas no curso-intervenção, como revelado na fala abaixo:

Com a dinâmica do curso, levamos a teoria para casa, estudamos, voltamos aqui e debatemos, e, por isso, achamos que nosso trabalho foi valorizado, qualificando as ações desenvolvidas nas visitas domiciliares e no atendimento individual e de grupo (GFA5).

Algumas perguntas e problemas até então considerados difíceis puderam ser enfrentados e encarados de maneira ampliada, e os meios para avançar foram surgindo no decorrer da intervenção, conforme exemplos trazidos pelos profissionais matriculados, envolvendo, particularmente, a abordagem familiar, prática paradoxalmente pouco utilizada pelas equipes de 'saúde da família':

(...) a equipe tinha muitas dificuldades relacionadas à questão familiar e hoje é possível dizer que conseguimos manejar com facilidade esse tema, pois, finalmente, conseguimos compreendê-lo em sua totalidade (GFA7).

(...) através do debate feito com base em um caso, conseguimos refletir qual o significado para uma família ter uma de suas filhas presa, entender que, além de "bandida", essa pessoa também é filha, mãe ou avó... E, com o aprendizado dessa discussão, conseguimos avançar no tema, pensar novas formas de intervenção para as famílias que vivem situações de maior vulnerabilidade (GFB8).

Outro ponto importante destacado pelos profissionais como exemplo de mudança na prática clínica viabilizada pelo curso-intervenção diz respeito às questões envolvendo atividades em grupo. Segundo se mencionou, as constantes queixas de baixa adesão de usuários às práticas de grupo e as dificuldades envolvendo a estrutura física e de recursos humanos não mais deveriam ser vistas como fator de desalento; concluiu-se ser necessário refletir sobre os temas e as estratégias metodológicas, em geral inadequadas, que vinham sendo empregadas. O contato com estratégias dialógicas pareceram-lhes abrir novas formas para orientar a relação profissional-usuário.

Antes do primeiro problema/dificuldade que o centro de saúde enfrentava, nossa escolha era sempre suspender o grupo... Como se isso fosse algo simples, sem 
consequências, visto que entendíamos que se tratava de um plus, um acessório e, por isso, podia começar e acabar a qualquer momento (GFB3).

Os profissionais matriculados reconheceram que no cotidiano dos serviços de saúde observa-se uma supervalorização das ofertas individuais em detrimento das grupais, e isso favorece a atitude de sempre se preterir o grupo quando o serviço passa por dificuldades, como a falta de recursos humanos ou o aumento da demanda. Além disso, existe a necessidade de se integrar as atividades grupais ao processo de trabalho global do serviço e dos profissionais:

(...) no Caps, temos hoje um número reduzido de grupos (seis ou sete) e, quando a equipe organiza sua agenda, pouco espaço é dado ao grupo ou poucas conversas sobre esse tema acontecem. Quando nos damos conta, o grupo acabou e não conseguimos explicar ao usuário o motivo (GFAl1).

Os profissionais expressaram com clareza que a valorização das atividades grupais decorreu da reorganização do modelo de atenção e das práticas. Assim sendo, a ampliação das atividades grupais voltadas para promoção dependeria de investimento coletivo, corresponsabilizando a equipe, usuários e gestores conforme descrito abaixo:

(...) o papel do apoiador do distrito é uma peça-chave para consolidar os grupos no cardápio de ofertas dos serviços de saúde (GFB10).

Causou surpresa o discurso dos profissionais sobre território e práticas comunitárias, fora da unidade de saúde. Afinal, o território é entendido como um tema que já foi totalmente absorvido pelas equipes, visto que a "territorialização" é uma das principais diretrizes do SUS. Sem dúvida, ele está imerso no cotidiano das equipes, mas pareceu-nos que ainda é abordado, principalmente sob o aspecto epidemiológico, ou, quem sabe, de uma perspectiva mais reduzida de divisão da população adstrita aos prontuários familiares, limitando-se a uma descrição com argumentos estereotipados como "péssimas condições de higiene", "condições precárias de moradia", conforme já foi apontado por outros investigadores (Oliveira e Furlan, 2008).

Assim, segundo o relato dos profissionais, os encontros possibilitaram a realização de uma reflexão sobre o território para além das amarras geográficas/epidemiológicas, proporcionando um olhar diferente, uma nova maneira - não uma maneira única - de se pensar o território como algo dinâmico, que pode ser extremamente diferenciado e capaz de potencializar as intervenções cotidianas. 
No debate sobre o território, ele foi comparado a uma bolsa feminina, artesanal, pequena e sem vida, e também ao fundo do mar, pois traz tamanha vastidão e complexidade (GFB2).

(...) na nossa abrangência existe uma grande área de tráfico de drogas. Com o curso, conseguimos refletir e compreender o quanto a presença dos traficantes, do código moral que existe nestas áreas, afeta a saúde das pessoas. Conseguimos, principalmente, visualizar outras maneiras de intervir, levando em consideração esse contexto (GFA10).

\section{A dimensão político-institucional}

A interação de profissionais de vários serviços no espaço do curso-intervenção foi um aspecto importante na efetivação da capacidade dos profissionais para pensar um processo de trabalho em equipe compondo redes de atenção. Os profissionais matriculados no curso-intervenção referiram que houve a constituição de redes de atenção reais, criadas no espaço de discussão e entendidas como algo diferencial no processo de compreensão do funcionamento prático da rede e de suas atribuições, facilitando a visualização do trabalho integrado por meio do reconhecimento dos serviços parceiros, conforme relato abaixo:

(...) pois uma coisa é sabermos que esses serviços existem; outra coisa bem diferente é conviver em um espaço coletivo como o curso, discutindo casos, conhecendo ferramentas dentro do sistema de que podemos usufruir, vendo os diferentes pontos de vista dos profissionais do Caps, da gestão e criar várias possibilidades de intervenção (GFC7).

Os profissionais destacaram que a opção do curso-intervenção em misturar os serviços que interagem dentro de um mesmo território foi pensada como uma possibilidade de implantar novas formas de aproximação, uma vez que, ao entender melhor limites, fragilidades e potências de cada serviço, houve o resgate do sentido e significado singulares para cada um dos profissionais, conforme o exemplo a seguir:

(...) no espaço do curso, olhamos um para o outro, nos conhecemos, vamos além do contato telefônico, quebramos a rotina, rompemos com os nossos preconceitos (GFB9).

Entretanto, essa aproximação tão intensa entre os serviços e suas equipes não é algo que tenha se desenrolado de maneira tranquila, pois em todas as organizações há limitações, frustrações, dificuldades de comunicação, 
desencontros, divergências... Assim, foram observados vários conflitos nas relações institucionais que ocasionaram forte sentimento de incômodo durante várias discussões de caso.

A maioria dos profissionais/alunos considerou positivo o fato de conseguirem identificar os conflitos institucionais e, mais, de falar sobre eles - uma vez que esses conflitos somente surgiram partindo-se do princípio de que os diferentes serviços estavam próximos e que as discussões mereciam ser feitas. Ou seja, em alguma medida as equipes conseguiram conversar. Já outros profissionais/alunos entenderam que os conflitos eram esperados, uma vez que o coletivo composto para o curso, com profissionais e serviços diferentes, era artificial, não fazia parte da rotina da gestão do SUS. Na opinião deles, esse espaço fez grande diferença, pois o processo de reflexão desencadeado permitiu identificarem-se as diversas formas de conduzir, de lidar com esse tipo de incômodo, sem cair na armadilha do apontar "um serviço faz e o outro simplesmente não faz".

Em relação ao trabalho em equipe, observou-se um relato consensual dos profissionais matriculados, particularmente quando se tratava da importância e do significado desse dispositivo na produção de práticas de saúde ampliadas e compartilhadas, configurando-se um ponto de equilíbrio para lidar com várias demandas, conforme o relato abaixo:

(...) com a equipe auxiliando, fica mais fácil lidar com a questão de que não sabemos tudo, de que não temos que resolver tudo e dar respostas para todos os problemas de saúde que os usuários nos apresentam no dia a dia. Não precisamos fazer projetos terapêuticos maravilhosos para todos os usuários e sim para os que apresentam maior risco e vulnerabilidade.... Existem casos tão complexos que a discussão sobre eles nunca termina, e o principal disso tudo é que não há receita pronta. O que existe é a possibilidade de construção coletiva de algumas prováveis saídas (GFD5).

Contudo, apesar de reconhecerem a importância do trabalho em equipe, os profissionais também relataram que, na prática, há dificuldade para o funcionamento produtivo das equipes. Consideraram que o espaço do curso-intervenção permitiu que refletissem sobre problemas e incômodos decorrentes do funcionamento real das equipes e isso serviu como disparador da necessidade de valorização do trabalho em equipe, uma vez que a rotina - sempre intensa, com problemas de saúde atravessados por vários fatores físicos, psicológicos e sociais - acabava resultando, inconscientemente, em certo mecanismo de esquecimento intencional:

(...) com os debates no espaço do curso, muitas vezes ficamos mais atentos ao olhar do outro. Afinal, estamos trabalhando em equipe, contando com o colega, 
e devemos nos esforçar para que ele conte conosco também. Assim, temos maior clareza para identificar o que estamos fazendo, o que estamos construindo, mesmo com as limitações, e fica fácil afirmar que estamos avançando nessa questão (GFC4).

Vale ressaltar que o discurso da valorização do trabalho em equipe não está desvinculado das dificuldades enfrentadas no cotidiano para se efetivar essa organização do processo de trabalho. Os profissionais/alunos consideraram que, muitas vezes, o trabalho em equipe de fato resolutivo ainda ocorre raramente e não se evidenciam sinais que comprovassem estar essa diretriz se incorporando, definitivamente e em sua totalidade, à prática cotidiana dos serviços de saúde.

Surgiram, no espaço do curso-intervenção, duas propostas para a superação desse impasse. A primeira delas foi assumir que não existe modelo, ferramenta ou instrumento que, por si só, seja suficiente para lidar com as dificuldades do trabalho em equipe:

(...) para lidar com o trabalho em equipe e suas questões, temos de ir reinventando-nos no cotidiano, criando as nossas próprias ferramentas (GFB2).

A segunda proposta foi entender que há aspectos externos às equipes, questões burocráticas, políticas e institucionais, que as limitam. Assim, a aposta não deve basear-se apenas no empenho e comprometimento dos profissionais; é necessário construir uma abordagem ampla, que consiga unir todas as problemáticas que envolvem o tema para, inicialmente, compreendê-lo e, depois, propor formas viáveis de transformá-lo:

(...) a superação das dificuldades que envolvem o trabalho em equipe passa por algumas limitações que fogem do nosso alcance, como a falta de viaturas para a realização de visitas, a estrutura física inadequada dos serviços, entre outros... Não podemos criar uma utopia (GFB5).

Por fim, é importante destacar as questões levantadas no curso-intervenção envolvendo o tema do colegiado gestor e da cogestão. Tais questões foram, na opinião dos profissionais/alunos, uma das passagens mais gratificantes do processo, visto que a gestão participativa e suas formas de articulação dentro dos serviços de saúde têm se tornado uma das mais fortes bandeiras para resolver a crise que vem assolando o SUS em Campinas.

Para os profissionais matriculados no curso-intervenção, assim como na proposta do apoio, o colegiado gestor é um dos dispositivos para se efetivar a democracia institucional, a cogestão no dia a dia das unidades. É um espaço de disputa de saberes, de ruptura com a lógica hegemônica de poder. 
Segundo essa visão teórica, por meio da gestão participativa, poder-se-ia avançar na construção de algo com potencial transformador; dito de outra forma, a gestão participativa constitui um espaço no qual é possível colocar na roda os conflitos e especificidades do trabalho, derrotando-se o medo de explicitar as várias fraquezas que permeiam o cotidiano do trabalho em saúde.

A narrativa dos grupos focais confirmou essa visão política de que, nos espaços participativos, colegiado gestor e outros, é possível discutir os projetos institucionais (tanto do CS Aeroporto quanto do Caps David). Os relatos confirmam essa possibilidade:

(...) esses espaços possibilitam, quando trabalham na lógica da cogestão, imprimir o ritmo do serviço, avaliar a qualidade do atendimento que está sendo prestado, monitorar as ações de saúde realizadas e, principalmente, definir de que modo é possível construir a legitimidade social do serviço junto da comunidade (GFC8).

Contudo, em ambos os locais, reconheceu-se a existência de vários impasses e dificuldades enfrentados para que o colegiado desempenhe seu papel. Segundo os profissionais/alunos, é possível compreendê-los e dividi-los em quatro fatores principais.

O primeiro fator está diretamente ligado ao cenário institucional do SUS Campinas, ou seja, à dificuldade de fixar os profissionais nos serviços. Um exemplo disso é que, nos dois serviços analisados, no início de 2010, os colegiados foram suspensos por causa da falta crônica de recursos humanos e da dificuldade das equipes para reorganizar seus processos de trabalho. Tais situações, recorrentes no contexto do SUS Campinas, têm enfraquecido esse dispositivo porque, quando o grupo ganha confiança para enfrentar os obstáculos trazidos pela gestão compartilhada, um dos seus membros é desligado, seja por demissão ou por sobrecarga de trabalho.

O segundo fator se refere à postura autoritária regularmente adotada pela gestão central da Secretaria Municipal de Saúde de Campinas e à automática diminuição da autonomia tanto das equipes de saúde quanto dos distritos sanitários. Tal postura é vista de maneira negativa pelos profissionais matriculados no curso-intervenção, pois tem fortalecido a reprodução vertical de poder; assim os colegiados, que buscam alternativas de compartilhar o poder, estão perdendo sua razão de existir e assumindo um posicionamento apático. Entretanto, os profissionais/alunos mencionaram saídas para superar esse autoritarismo dos gestores e fortalecer os colegiados:

(...) uma saída é criar e estimular, dentro dos serviços, movimentos de resistência, movimentos que possam manter viva, no cotidiano das equipes, a importância de trabalhar com relações horizontais e decisões compartilhadas, mesmo não sendo esse o posicionamento dos gestores (GFC3). 
Essa discussão gerou efeitos concretos e positivos, porque os colegiados do Centro de Apoio Psicossocial e do Centro de Saúde foram reativados no decorrer das discussões. Consideramos ter sido esse um movimento de resistência, visto que estimulou os profissionais matriculados no curso-intervenção a exercerem o seu protagonismo, buscando a cogestão em parceria com a equipe e os usuários, seja nos conselhos locais ou no municipal.

O terceiro fator mencionado pelos profissionais/alunos é a dificuldade de envolver/encantar os trabalhadores a fim de que assumam uma postura ativa em geral e, em particular, diante da gestão participativa, fortalecendo com isso o SUS e a democracia institucional. Eles apresentam duas explicações para esse fenômeno:

(...) observa-se na maioria dos serviços a permanência de uma cultura na qual a gestão é de responsabilidade apenas dos profissionais que ocupam cargos de gestão. Ouve-se repetidamente pelos corredores que não há razão para existir colegiado, visto que existe um coordenador de serviço que recebe aporte financeiro [salário] e que, por isso, tem obrigação de solucionar todos os problemas de gestão do serviço (GFC2).

(...) existe um entendimento equivocado do colegiado gestor, no qual o mesmo é associado a formas de exercer o poder sobre os outros. Assim, quem compõe o colegiado, teria supostamente maior poder na instituição que os outros trabalhadores (GFC9).

Tais equívocos, na opinião dos profissionais/alunos, são os maiores obstáculos que os colegiados e conselhos enfrentam no dia a dia. Como resultado desse clima, percebeu-se que a maioria das equipes se organizava de forma pouco solidária e sua capacidade de compor pactos e de estabelecer consensos, mesmo nas diferenças, diminuía drasticamente.

Construíram-se várias explicações para os jogos de poder que os serviços de saúde enfrentam no seu cotidiano e para a fragilidade dos profissionais e usuários quando há necessidade de enfrentá-los. O curso-intervenção problematizou o tema em vários momentos, porém não conseguiu criar alternativas para avançar na compreensão da questão para que realmente a democracia se efetive no interior das instituições de saúde.

O último obstáculo relatado pelos profissionais/alunos é o pouco conhecimento, por parte da maioria dos trabalhadores, de como se configura e, especialmente, de qual o significado da gestão colegiada. Na maioria das faculdades, não se investe na formação de profissionais para trabalhar em equipe. Sabe-se que os profissionais de saúde precisam uns dos outros; no entanto, a formação da maior parte deles se dá de maneira isolada, valorizando práticas que se pautam na lógica e no interesse das categorias e setores. 
Assim, é importante viabilizar, dentro dos serviços, processos de formação diferenciados, como o proposto neste artigo, processos que possam ser singulares e que ajudem os profissionais a trabalharem em equipe, em redes de atenção que fortaleçam a composição e a efetivação de espaços coletivos, onde seja possível unir o projeto institucional aos projetos individuais, buscando a construção de práticas de saúde ampliadas e compartilhadas.

\section{A dimensão do governo de si mesmo}

Observou-se um consenso entre os profissionais/alunos de que o curso-intervenção contribuiu na organização do trabalho cotidiano para além das questões técnicas e formais, influenciando também áreas que envolvem a relação com o usuário, os prejulgamentos, censuras e valores.

(...) o curso mexeu bastante com todos nós, nos fez repensar alguns comportamentos e preconceitos na relação com o outro e conosco (GFC5).

Para os profissionais/alunos, isso ocorreu por dois motivos:

(...) primeiramente porque, dentro do próprio grupo, havia uma figura que sempre trazia grande tensão, fazia o papel de advogado do diabo, e sempre nos fazia repensar nossas posturas com relação ao usuário. Em segundo lugar, porque no espaço do curso, durante as discussões de caso, sempre havia um olhar diferente, uma possibilidade de compartilhar as próprias tristezas e frustrações que o caso trazia, mudando assim a forma de intervenção (GFD8).

(...) o curso possibilitou conhecer uma linguagem que antes era desconhecida e, assim, a forma de se comunicar com os usuários, colegas de trabalho e gestores passou a ser diferente, uma vez que conseguimos tanto compreender melhor os significados que permeiam o processo de trabalho quanto também identificar as dificuldades e enfrentá-las coletivamente (GFC2).

Perceber esse resultado foi de extrema importância, porque ele demonstra que, adotando a Metodologia de Apoio Paideia, é possível contribuir para a consolidação de mudanças efetivas na prática profissional para além do discurso, pois também foi possível trabalhar com a subjetividade dos profissionais matriculados no curso-intervenção.

Além disso, observou-se em vários encontros do curso-intervenção momentos de mudança (modificação de uma situação) e de ruptura (introdução de uma nova situação). Esse processo pode ser resumido em quatro movimentos básicos. 
O primeiro foi perceber que todos os profissionais matriculados no curso-intervenção enfrentaram dificuldade para se abrir e sair da sua zona de conforto. Portanto, quando vivenciamos um processo de formação em que a mudança não é uma finalidade, mas um meio de efetivar novas práticas de saúde, é necessário lembrar que cabe aos apoiadores horizontais orientá-los nesse percurso, pois é difícil para os profissionais construir uma nova lógica de trabalho, visto que isso está diretamente ligado à sua identidade.

Já o segundo movimento é bem simples e pode ser descrito da seguinte forma: toda e qualquer mudança, por menor que ela seja, inclusive as proporcionadas pelo curso-intervenção, gera reações positivas e negativas. Assim, cabe aos apoiadores horizontais compreender, experimentar e compartilhar com os profissionais matriculados cada novo posicionamento, visto que, segundo o Método de Apoio Paideia, é difícil para o coletivo avançar sem suporte.

O terceiro demonstrou que a flexibilidade em relação ao programa do curso e aos elementos teóricos e metodológicos é uma característica importante, pois, dessa maneira, é mais fácil identificar a demanda, a encomenda e o pedido que os profissionais matriculados no curso-intervenção sinalizam.

Segundo nossas diretrizes, cabe aos apoiadores horizontais a responsabilidade de sempre buscarem a autonomia do grupo apoiado. Para o Método de Apoio Paideia, a autonomia não significa independência ou descompromisso absoluto; pelo contrário, a ampliação da autonomia depende da capacidade de o sujeito reconhecer e lidar com a rede de dependência na qual todos estão inevitavelmente mergulhados (Campos, 2010).

Com o decorrer do processo de formação, percebeu-se que o conceito de autonomia não é estático nem absoluto, mas sim um processo dinâmico que implica perdas ou aquisições sempre gradativas. Além disso, nos encontros em que o tema foi abordado, os profissionais/alunos afirmaram ainda não estarem preparados para lidar com a autonomia no cotidiano de seu trabalho, principalmente na relação com os usuários. Segue relato de um profissional:

(...) entendo que autonomia é a possibilidade do outro fazer escolhas, com ou sem apoio de terceiros. Nós, profissionais de saúde, estamos despreparados para lidar com a autonomia dos usuários porque não faz parte da nossa cultura poder escolher... Assim, estranhamos essas possibilidades que o exercício da escolha, da autonomia trazem (GFD3).

Mesmo estimulando, em vários encontros, o desenvolvimento da autonomia, observou-se que grande parte dos profissionais/alunos ainda havia refletido muito pouco sobre a autonomia dos usuários nos serviços de saúde. Na maioria das situações, as equipes ainda se fechavam diante da iniciativa dos usuários em se tornarem mais autônomos, tendendo para propostas prescritivas e normativas. 
Com o passar do tempo, foi possível entender que problematizar questões práticas que envolvem o conceito de autonomia dos usuários e da própria equipe ainda eram um ponto de dificuldade, porque o curso-intervenção não conseguiu avançar na reflexão sobre a concepção que cada um dos profissionais tinha de autonomia.

Segundo Onocko e Campos (2007), as práticas de saúde podem ser desenvolvidas para as pessoas e comunidades ou junto com as pessoas e comunidades. É necessário criar um movimento para escapar das receitas prontas e, assim, interromper a visão estereotipada sobre nós e os outros, na qual são sempre os outros que têm de mudar, aprender, incorporar.

Portanto, consideramos que minha atuação como apoiadora horizontal - sob a supervisão direta do professor Gastão Wagner - foi um fio condutor para desenvolver a reflexão sobre autonomia com os profissionais/alunos. Buscamos estimular um movimento que colocasse o grupo no trilho de suas próprias mudanças, partindo do princípio de que, para mudar, é importante manter-se aberto a todas as perguntas, sonhar, apostar e fazer diferente, criando novas possibilidades e desenhando uma função clínica ampliada que pode ser compreendida como uma função ética e articuladora.

\section{Considerações finais}

O presente artigo buscou registrar as possíveis contribuições do Apoio Institucional Paideia como estratégia para a educação permanente em saúde, analisando os efeitos de um curso-intervenção. O estudo não trabalhou apenas com teorias; tomou da ação prática o desafio de construir algum conhecimento, partindo da história vivenciada pelos profissionais de saúde de Campinas matriculados no curso-intervenção. Profissionais sujeitos, imersos em seu contexto de vida, motivados pelo desejo de mudanças ou frustrados pelas mudanças que não acontecem. Profissionais comprometidos com diferentes tipos de interesses, pautados por projetos pessoais ou coletivos. Profissionais crentes em saberes e valores, ou carregados de dúvidas e de insegurança a respeito do futuro.

Vale ressaltar o desafio que é desenvolver uma pesquisa intervenção do tipo apoio em um ambiente complexo como o do SUS Campinas. E questões institucionais como a instabilidade dos contratos, a alta rotatividade das equipes, a greve dos servidores, entre outras, influenciaram diretamente todo o estudo.

O processo de formação vivenciado provocou mudanças nas práticas clínicas, visto que os profissionais/alunos relataram avanços na forma de lidar com situações do cotidiano que anteriormente representavam dificuldades, como a abordagem familiar, o trabalho com grupos, o entendimento do território como um espaço de intervenção, entre outras. 
A vivência singular trouxe também um olhar diferente para o interior das equipes, visto que os profissionais/alunos reconheceram a importância da equipe para compartilhar as angústias e frustrações que o trabalho em saúde proporciona, apesar de ainda identificarem impasses para a efetivação dessa dinâmica coletiva no interior dos serviços.

No que se refere à relação com a gestão, vale destacar que foram reorganizados e retomados os Colegiados gestores dos serviços que haviam sido suspensos em decorrência de problemas originados do contexto institucional.

Percebeu-se que o espaço de formação experimentado também trouxe mudanças na gestão de 'si mesmo', uma vez que foram analisados de maneira reflexiva preconceitos e valores, e construídas novas formas de se relacionar, especialmente com os usuários, por meio da metodologia de discussão de casos e pela construção de projetos terapêuticos compartilhados. Tal aspecto é de grande relevância porque o método parte do pressuposto de que as mudanças na prática clínica, para serem efetivas (e irem além do discurso), devem mobilizar o subjetivo de cada um dos profissionais matriculados no curso-intervenção.

Ao exercemos a função de apoiadores, é necessário pensar em nós mesmos e nas implicações de nossas atitudes sobre os outros. Vale destacar que a formação do apoiador ocorre mediante prática reflexiva e na discussão dessas práticas em um espaço coletivo formal com outros apoiadores. Ou seja, a formação acontece no processo dinâmico de apoiar um coletivo organizado. Assim, é algo diferente do ensino prescritivo.

O apoiador é a figura que pode ajudar a equipe a refletir acerca de suas práticas cotidianas, com o objetivo de aumentar a capacidade de intervenção sobre a realidade. Assim, ele funciona tanto como um espelho quanto como alguém que traz vozes, experiências e saberes de fora do grupo, alguém capaz de reconhecer os valores e expressar propostas de mudança, por meio da composição de uma ética para si mesmo e para o outro (ou com o outro).

Essa ética se baseia no fato de que o ser humano, para sobreviver, cria sociabilidade, conquanto haja regras para tanto, leis que limitam os desejos e interesses individuais em favor dos interesses e desejos do outro. $\mathrm{O}$ apoiador se coloca nesse processo para fazer um tipo de mediação/coordenação entre os interesses e desejos da equipe, usuários e gestores.

Por fim, conclui-se que o estudo apresentou evidências de que não somente é possível, mas é fundamental investir em novos métodos de formação que têm como fio condutor a prática e as vivências que buscam entender a realidade, num primeiro momento, para depois tentar transformá-la.

Entretanto, não se pode perder de vista que não é possível mudar os rumos do SUS municipal, estadual ou nacional somente investindo na formação de equipes. É essencial compor projetos comuns na diferença; criar 
possibilidades para além dos limites administrativo-financeiros; abrir rodas de discussão com sindicatos, trabalhadores, movimentos sociais, usuários, gestores e universidades; e construir um movimento ético-político para a produção de uma saúde melhor para toda a sociedade.

\section{Colaboradores}

Cristiane Pereira de Castro participou da concepção, coleta de dados, análise de dados e redação do artigo. Gastão Wagner de Sousa Campos atuou na concepção, orientação, redação do artigo e revisão.

Resumen Se trata de una investigación-intervención, de tipo apoyo. En esta investigación se evaluaron los efectos del curso-intervención Cogestión de la Clínica Ampliada y Compartida, especialmente en lo tocante a la incorporación de saberes que ayudan a los profesionales a desarrollar la capacidad de trabajar en red, en equipo y con cogestión del trabajo en la salud. El curso se ofreció a los profesionales integrantes de los equipos del Centro de Salud Aeropuerto y del Centro de Atención Psicosocial David Capistrano y a colaboradores institucionales del Distrito Sudoeste de Campinas, San Pablo. Para la producción de datos, se utilizaron dos técnicas: observación y realización de grupos focales de evaluación con los profesionales que participaron en el curso. Se constataron cambios relevantes en los profesionales en lo que respecta a las dimensiones clínica, política e institucional y del gobierno de sí mismos.

Palabras clave Capacitación en salud; apoyo institucional; Método Paideia; educación permanente en salud. 


\section{Notas}

1 Universidade Estadual de Campinas, Campinas, São Paulo, Brasil.

Doutoranda em Saúde Coletiva pela Universidade Estadual de Campinas, Campinas. <crispcastro@yahoo.com.br>

Correspondência: Departamento de Saúde Coletiva, Faculdade de Ciências Médicas, Universidade Estadual de Campinas (Unicamp), Cidade Universitária Zeferino Vaz, CEP 13084-971, Caixa Postal 6111, Campinas, São Paulo, Brasil.

2 Faculdade de Ciências Médicas da Universidade Estadual de Campinas, Campinas, São Paulo, Brasil.

Livre-docência pela Universidade Estadual de Campinas. <gastaowagner@mpc.com.br>

$3 \mathrm{O}$ artigo é resultado da dissertação de mestrado da autora principal intitulada Avaliação da utilização do Método de Apoio Paideia para a formação em saúde: clínica ampliada e cogestão, e o estudo integrou o projeto de pesquisa "Avaliação participativa do Método de Apoio Paideia na formação de trabalhadores em clínica ampliada e compartilhada", que recebeu apoio financeiro do convênio Programa de Pesquisa para o SUS, da Fundação de Amparo à Pesquisa do Estado de São Paulo (Fapesp), do Conselho Nacional de Desenvolvimento Científico e Tecnológico (CNPq) e da Secretaria Estadual de Saúde de São Paulo.

\section{Referências}

BALINT, Michael. O médico, o paciente e sua doença. Rio de Janeiro: Livraria Atheneu, 1988.

BRANDÃO, Carlos R. Pesquisa participante. São Paulo: Brasiliense, 1981.

CAMPOS, Gastão W. de S. Um método para análise e cogestão de coletivos. 2. ed. São Paulo: Editora Hucitec, 2005.

Efeito Paidéia e humanização em saúde: cogestão e não violência como postura existencial e política. In: BRASIL. Ministério da Saúde. Secretaria de Atenção à Saúde. Política Nacional de Humanização. Cadernos HumanizaSUS. Brasília: Ministério da Saúde, 2010. p. 129-141. (Atenção Básica; v. 2).

CASTRO, Cristiane de P. Avaliação da utilização do método de Apoio Paidéia para a formação em saúde: clínica ampliada e cogestão. 2012. 246 f. Dissertação (Mestrado em saúde Coletiva) - Campinas, Faculdade de Ciências Médicas, Unicamp, 2012.

CECCIM, Ricardo Burg. Educação permanente em saúde: descentralização e disseminação de capacidade pedagógica na saúde. Ciência \& Saúde Coletiva, Rio de Janeiro, v. 10, p. 975-986, 2005.

CUNHA, Gustavo T. Grupos Balint Paidéia: uma contribuição para a cogestão e a clínica ampliada na Atenção Básica. 2009. 254f. Tese (Doutorado em Saúde Coletiva) - Campinas: Departamento de Medicina Preventiva e Social/FCM/Unicamp, 2009.

GAJARDO, Marcela. Pesquisa participante: proposta e projetos. In: BRANDÃO, Carlos R. (Org.). Repensando a pesquisa participante. São Paulo: Brasiliense, 1999. p. 15-50. 
MASSUDA, Adriano. O método do apoio Paidéia no hospital: descrição e análise de uma experiência no HC-Unicamp. 2010. 240f. Dissertação (Mestrado em Medicina Preventiva e Social) - Campinas: Departamento de Medicina Preventiva e Social/FCM/Unicamp, 2010.

MINAYO, Maria Cecília S. O desafio do conhecimento: pesquisa qualitativa em saúde. São Paulo: Hucitec; Rio de Janeiro: Abrasco, 2000.

MINAYO, Maria Cecília S. et al. Métodos, técnicas e relações em Triangulação. In: MINAYO, Maria Cecília S.; ASSIS, Simone G; SOUZA, Ednilsa R. (Org.). Avaliação por triangulação de métodos: abordagem de programas sociais. Rio de Janeiro: Editora Fiocruz, 2005. 32 p.

MONCEAU, Gilles. Transformar as práticas para conhecê-las: pesquisa-ação e profissionalização docente. Revista Educação e Pesquisa, São Paulo, v. 31, n. 3, p. 467-482, 2005.

MORGAN, David. Focus groups as qualitative research. Thousand Oaks: Sage Publications, 1997.
OLIVEIRA, Gustavo N.; FURLAN, Paula G. Coprodução de projetos coletivos e diferentes 'olhares' sobre o território. In: CAMPOS, Gastão W. de S.; GUERRERO, André V. P. (Orgs.). Manual de práticas de atenção básica: saúde ampliada e compartilhada. São Paulo: Editora Hucitec, 2008. p. 247-272.

ONOCKO, Rosana C. Pesquisa qualitativa em políticas, planejamento e gestão em Saúde Coletiva. In: BARROS, Nelson F.; CECATTI, José G.; TURATO, Egberto R. (Orgs.). Pesquisa qualitativa em saúde: múltiplos olhares. Campinas: Editora Komedi, 2005. p. 261-71.

ONOCKO, Rosana C.; CAMPOS, Gastão W. de S. Coconstrução de autonomia: o sujeito em questão. In: CAMPOS, Gastão W. de S. et. al. (Org). Tratado de Saúde Coletiva. São Paulo: Editora Hucitec, 2007. p. 669-88.

RICOEUR, Paul. Tempo e narrativa. Campinas: Papirus, 1997. (Tomo I).

ROCHA, Marisa L.; AGUIAR, Katia F. Pesquisa-intervenção e a produção de novas análises. Psicologia: Ciência e Profissão, Brasília, v. 23, n.4, p. 64-73, 2003.

Recebido em 29/06/2012

Aprovado em 02/01/2013 